\title{
POLÍTICA DE COBRANÇA PARA PEQUENA EMPRESA
}

\author{
Luiz Ricardo Mangili
}

Graduado em Administração de Empresas pela Faculdade Interior Paulista FIP. Pós Graduado em Marketing pela UNIP. Professor Universitário e Consultor de Empresas.

\begin{abstract}
RESUMO:
O objetivo deste artigo é comprovar que através de ações preventivas e metodológicas é possível reduzir os riscos dos negócios sem comprometer a comercialização dos bens ou serviços, com uma aplicação adequada da política de cobrança. Foram coletadas informações em uma empresa de varejo, durante os períodos de Janeiro à Abril de 2008 e o mesmo período no ano de 2009, sobre o faturamento e os índices de inadimplência. Com a utilização das ferramentas de proteção ao crédito; análise da capacidade de crédito suportada pela pequena empresa; migração das contas em carteira para a utilização dos cheques e cartões de créditos; treinamentos com equipe do departamento de crédito; elaboração de políticas de crédito, cobrança e a conscientização de consumidores para a análise real do que e para que estão gastando, foram feitos monitoramentos pelo departamento de crédito e a política de cobrança, através do DRE - Demonstrativo de Resultados do Exercício. Criou-se o hábito medir os volumes de vendas com os valores das contas a receber, para rapidamente promoverem as ações de reduzir os valores em atrasos. Os resultados comparados ficaram claros, positivando a redução da inadimplência, trazendo para o caixa da empresa uma liquidez mais rápida, consolidando o fluxo de caixa mais próximo da realidade da pequena empresa.
\end{abstract}

Palavras-chave: Inadimplência. Crédito. Política de Cobrança. Liquidez. Caixa.

\section{INTRODUÇÃO}

O objetivo do artigo é comprovar que através de ações preventivas e metodológicas é possível reduzir os riscos dos negócios sem comprometer a comercialização dos bens ou serviços. Com interação de toda equipe, com treinamentos e um dossiê em forma de cartilha, facilitará e orientará o uso correto das ferramentas propostas.

Prazeres (2008 a) aponta que, é importante focar e explicar como é realizado e concedido o processo de crédito nas empresas. Pode ser um facilitador existente para as 
vendas mas, por outro lado, pode-se considerar o crédito um fator de risco para as empresas; afinal, com isso, as concessões de crédito deverão estar cada vez mais presentes nas relações comerciais, devido sua importância para a prevenção da inadimplência que vem crescendo nas pequenas empresas de varejo. Motivos esses que partem desde a má análise de crédito, até o preenchimento inadequado dos cadastros dos consumidores.

Para isso, a redução da inadimplência deverá estar correlacionada à metodologia da prevenção, através da análise de crédito, equipes e departamentos bem treinados e cadastros bem elaborados. Toda essa metodologia e proposta abordada neste artigo, deve ser elaborada em formato de cartilha e serem utilizadas como ferramentas indispensáveis por todos os colaboradores e empresários que queiram manter protegida a saúde financeira de sua empresa (DA SILVA, 2007).

Mesmo percebendo mudanças nos comportamentos de créditos por parte dos agentes financiadores e por uma minoria de consumidores, Blatt 1999 aponta que, muitos empresários não se preocupam em analisar a parte creditícia dos consumidores. Para tanto, devem-se escolher os métodos adequados e preventivos em relação às análises de créditos e as formas de cobrança junto aos inadimplentes, onde se deve levar em conta se esse inadimplente é do tipo que merece voltar a ser cliente ou não.

O objetivo do artigo é comprovar que através de ações preventivas e metodológicas é possível reduzir os riscos dos negócios, pois, segundo Leoni;Leoni (1997) quando se entrega um bem ou serviço mediante uma promessa de pagamento em data futura, se estabelecem uma relação de confiança entre ambas as partes envolvidas no negócio sem comprometer a comercialização dos bens ou serviços

\section{REFERENCIAL TEÓRICO}

\subsection{Cobrança}

$\mathrm{Na}$ área de cobrança, a política é de cobrar energicamente os valores vencidos, e reutilizando-se todo o processo de recebimento de duplicatas através de instituições bancárias. Tem como metas receber um montante de dinheiro no mês corrente e reduzir valores de duplicatas vencidas. Num mercado cada vez mais competitivo, em que a qualidade e o preço dos produtos e serviços costumam ser nivelada pela concorrência, o diferencial na área de crédito e cobrança esta no talento humano, visto como a chave para maximizar o desempenho e os resultados de uma empresa. Hoje, o acesso às informações para análise de crédito é muito mais ágil. Com um tempo menor de análise, o papel do analista se transforma através do 
surgimento de oportunidade de novos negócios, alcançando também a prospecção, a potencialização de vendas, a higienização de cadastros e o gerenciamento de carteiras (PRAZERES, 2008 b).

Ao oferecer crédito para pessoas físicas de menor poder aquisitivo, pode-se pressupor que aja certo índice de inadimplência por parte dos mesmos. Nesse momento, entram em cena os cobradores, que podem ser bons ou maus na execução de suas atividades. Há os que fazem uso de práticas abusivas, que pretendem receber o valor a qualquer preço, e há também os que sabem aproveitar bem a situação para receber o valor da dívida e ainda manter um elo de fidelidade com os clientes (PRAZERES, 2008 b).

O cobrador que utilizar meio que exponham seu cliente ao ridículo segundo Blatt (1999), como ameaças, coação, linguagem violenta, constrangimentos, etc., estarão sujeito à pena e multas especificas. Portanto, para evitar esses dissabores, é importante que o profissional da área de cobrança saiba como lidar com os seus clientes inadimplentes de forma que a cobrança não seja uma situação negativa, um bicho de sete cabeças que, na maioria das vezes, traz grandes prejuízos e aborrecimentos aos clientes.

\subsubsection{A cobrança e a justiça}

Quando houver a necessidade de se efetuar as práticas de cobrança segundo Prazeres (2008 b), dentro de alguns mecanismos e os cadastros estiverem bem preenchidos e analisados, as ações passarão a ter um resultado mais rápido e positivo, como será observado a seguir algumas práticas de cobranças:

a) Ação ordinária de cobrança: aplicável a todos os títulos, inclusive cheques após seis meses da data de emissão;

b) Ação executiva: aplicável a títulos executivos judiciais e extrajudiciais, como a sentença judicial, cheque (com menos de seis meses da data de emissão) promissória, duplicata, letra de câmbio, contrato público ou particular assinado entre as partes com duas testemunhas;

c) Ação monitória: aplicável a todos os títulos especialmente as "notinhas", "orçamentos" e demais documentos de dívida não-enumerados como título executivo;

d) Ação de busca e apreensão: aplicável no caso de locação ou venda de bens imóveis; caso haja o inadimplemento, o credor ajuíza ação perante o Juiz de Direito, requerendo a devolução do bem; 
e) Ação de despejo por falta de pagamento juntamente com ação de cobrança: aplicável somente para locação de imóvel.

\subsubsection{Política de cobrança}

Para Da Silva (2007) nenhuma empresa sobrevive sem vendas, "mas tão vital quanto vender é receber", por isso da importância de criar uma política de cobrança e as formas como serão efetuadas. A política de cobrança é um conjunto de fatores, normas, métodos e diretrizes, criadas pelos gestores da empresa e que normatiza as ações e procedimentos de recuperação de créditos.

Prazeres (2008 b) diz que, na definição da política serão determinadas quais as ações a serem adotadas e a forma de atuação na condução da cobrança. Ela pode ser formal, ou seja, escrita ou informal, não escrita. A política escrita, que pode ser publicada através de um Manual de Normas de Cobrança, possui a vantagem de proporcionar aos envolvidos no processo, regras claras de atuação. Por outro lado, pode tirar flexibilidade de alguns procedimentos.

Segundo Blatt (1999) o manual de políticas deverá trazer informações e normas para os procedimentos de cobrança, que contenham os métodos e técnicas a serem utilizados em relação aos tipos de devedores, aos valores inadimplidos, prazos máximos para cada etapa de cobrança, valores mínimos para cobrança judicial, enfim, todo tipo de informação que conduzirá ao processo de cobrança.

Para tanto, Blatt (1999) os gestores da empresa, juntamente com sua assessoria jurídica e com os encarregados da área de cobrança, deverão definir como serão os procedimentos na gestão dos valores em atraso, transcrevê-los e publicá-los, para conhecimento dos envolvidos nas áreas de cobrança, crédito e comercial.

\subsubsection{Eficácia na cobrança}

A política global de cobrança da empresa é determinada pela combinação de técnicas utilizadas de contato pessoal, telefone, concentração das contas mais perigosas, contas de valores expressivos e cartas. Também considera registro no SPC, envio da cobrança para escritórios especializados e procedimentos jurídicos (BLATT, 1999).

Prazeres (2008 b) mostra como se deve implantar uma rotina no setor de cobrança; e cada empresa terá seu ajuste necessário, a rotina é: 
a) Entre 5 e 10 dias de atraso, a empresa deve fazer contato por telefone com clientes de primeira compra, ou seja, que são novos e não têm histórico de compra. Se não for possível o contato telefônico, enviar primeiro aviso de vencimento;

b) Para clientes de segunda compra em diante, usar o contato telefônico ou o primeiro aviso entre 11 e 15 dias de atraso. No primeiro contato telefônico, identifique-se, informando seu nome, seu setor e a empresa. Logo após, diga que o telefonema é devido ao fato de não ter o setor de contas da empresa registrado o pagamento da prestação, até a presente data;

c) Entre 16 e 25 dias, os procedimentos de cobrança tendem a se uniformizar para cliente de primeira e segunda compra. Procure informar as consequências do não pagamento, corte do crédito para novas compras, pagamento de juros, multa, etc.

- Clientes de primeira compra: telefonema ou terceiro aviso de carta de cobrança.

- Clientes de segunda compra: telefonema ou segundo aviso de carta de cobrança e, após 5 dias sem resposta, enviar o terceiro aviso de carta de cobrança;

d) Após 15 dias, se não houver pagamento ou acordo, independentemente se for primeira ou segunda compra, envie o cobrador. Caso não localize o devedor no primeiro contato (telefone ou carta), envie cobrador imediatamente;

e) Entre 26 e 30 dias de atraso, telefonar ou enviar carta informando que será registrado no SPC, caso não efetue o pagamento.

f) Se após o envio do aviso de registro do SPC e em 4 dias o devedor não se manifestar, efetivar o registro no SPC;

g) Após registro no SPC, não houver nenhuma manifestação do devedor para acerto da dívida ou re-parcelar a dívida através de confissão de dívida ou composição, procurar empresa especializada em cobrança;

- Terceirize a cobrança quando for o caso, segundo Da Silva (2007, p.39):

i. Após as contas excederem o ponto de atraso máximo definido pela política de cobrança da empresa, por exemplo, 60 dias de inadimplência, pois, quanto mais rápido for movida uma ação efetiva de cobrança, mais rápido será o recebimento;

ii. Como a última alternativa, antes de uma ação judicial;

iii. Após terem fracassado as tentativas primárias de cobrança;

iv. Nos casos de cobranças de pequeno valor, que não justificam ações próprias por parte do credor. Nesse caso, elas poderão ser passadas para a empresa terceirizada de imediato;

v. Em cobranças complexas, complicadas ou difíceis.

- Perfil da empresa de cobrança segundo Da Silva (2007, p.59): 


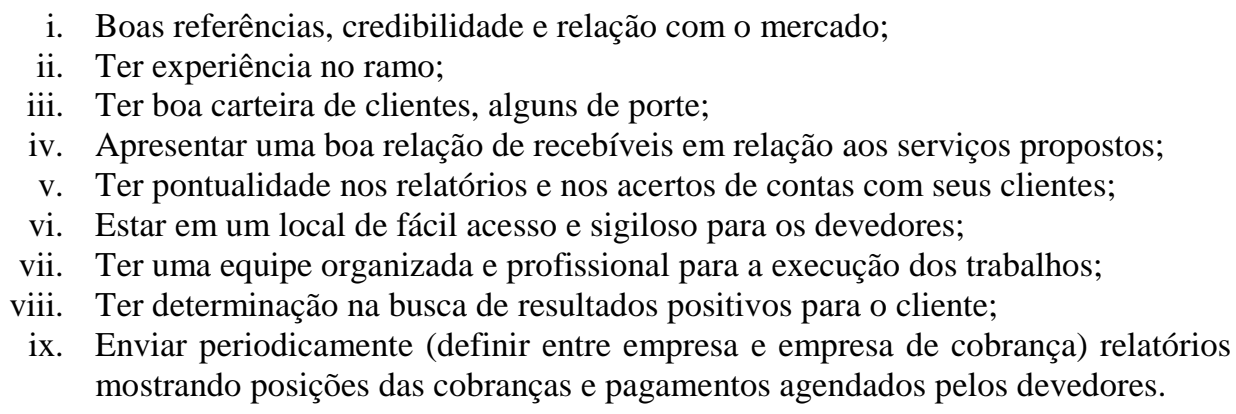

h) Todas as contas antigas, estipuladas pela empresa dentro da política de cobrança, exemplo, contas vencidas a mais de 240 dias não recebidas, promover a anistia, tentar entrar em contato como devedor e promover um recebimento parcial, para minimizar o prejuízo.

i) Todas as ligações que forem feitas pelos recuperadores de créditos, deverão ser planejadas antes, para entender o débito e a situação cadastral do devedor;

j) Sempre iniciar as ligações aos devedores, pontuando sempre dos maiores valores para os menores;

k) Se for um cliente que já recebeu alguma ligação, certifique sobre seu histórico ou até mesmo se foi feito algum acordo e não cumpriu;

1) No envio das cartas de aviso dos débitos, elas não poderão ter um texto coagindo o cliente e nem enviados nos locais de trabalho e para vizinhos;

m) O texto das cartas tem que ser breve, direto, claro e verdadeiro; evitar o uso de gírias técnicas e expressões agressivas;

n) Nas cartas haverá a obrigação de constar o nome completo do devedor, o número do título, contrato, cheque, etc. data da compra, vencimento da dívida e o valor principal;

o) Nunca colocar no lado externo da carta ou envelope os dizeres: cartas de cobrança, cartas ao devedor, cliente inadimplente, etc.;

p) Manter uma média de 6 (seis) a 8 (oito) linhas por carta aviso;

q) Evitar ao máximo, correspondências abertas.

Ainda na questão telefonema, Prazeres (2008 b) informa que, ele deve ser rápido, mas sem expressões atropeladas, tenha voz pausada e clara. Fale as palavras completamente, não corte sílabas, principalmente a última, use sempre dois nomes próprios para se dirigir ao cliente.

As empresas que registram seus inadimplentes com 30 dias após o vencimento têm um retorno imediato de mais ou menos $70 \%$ (setenta por cento) nos primeiros 30 dias após o registro, cerca de $20 \%$ (vinte por cento) com 60 dias e $10 \%$ (dez por cento) dos registros são considerados como retorno em longo prazo. As empresas que levam de 60 a 90 dias para 
registrar um débito em atraso, obtêm um retorno imediato de apenas $10 \%$ (dez por cento) dos registros, $70 \%$ (setenta por cento) levam até 6 meses para serem recebidos e o índice de retorno em longo prazo aumenta $20 \%$ (vinte por cento) (PRAZERES, 2008 b).

Da Silva (2007) aponta que as ações de cobranças para as pequenas empresas varejistas precisam ser programadas. Deve-se observar o momento mais próprio para uma cobrança, como final de mês, quando está próxima a data de pagamento de salários, ou então meio de mês, quando normalmente saem os adiantamentos de salários. Ter isso claro e definido através de planilhas eletrônicas ou físicas, pontuando e acompanhando junto com o pessoal da área de crédito e recuperação de dívidas, os cobradores.

\subsection{Inadimplência}

As perdas potenciais do crédito com a inadimplência ocorrerão sempre que as taxas de juros não acompanharem a evolução da inflação e os custos da empresa. Entenda-se que esse comportamento das taxas de juros influenciaria na qualidade de crédito e, portanto, na redução do retorno efetivo dos clientes nas vendas e prazo. Seria bom se todos os clientes pagassem suas faturas na data do vencimento, mas não é isso que acontece, uma vez que pode acontecer de o cliente adiar o seu pagamento (PRAZERES, 2008 a).

Nas empresas dos setores do comércio e de serviços, a inadimplência tem um aumento nos três primeiros meses do ano, em decorrência das vendas efetuadas no mês de dezembro. E é justamente nestes meses iniciais que ocorre a queda nas atividades destes setores empresariais, deixando assim muitos empresários em dificuldades, tendo em vista que contavam com o pagamento das vendas parceladas de final de ano, para suprir o baixo volume de vendas. Neste caso verificamos dois tipos de sazonalidade: a de aumento das vendas, que ocorre no final do ano, quando a maioria das pessoas recebe o $13^{\circ}$ salário, passando assim a consumir mais, sendo que grande parte das compras é feita de forma parcelada, por meio de cheque pré-datado, cartões de crédito ou financeiras. a de queda nas vendas ou atividades nos três primeiros meses do ano, porque a maioria dos consumidores está comprometida com outras despesas como: matrícula na escola, compra de material escolar, férias etc.(SEBRAE/RJ, 2009)

\subsection{Conceitos e análises de crédito}

O Crédito consiste no ato de confiar, acreditar. A confiança faz parte do nosso 
cotidiano, convivemos em sociedade porque acreditamos que outros agirão de acordo com regras ou padrões socialmente estabelecidos, ou seja, quando atravessamos a rua temos a confiança de que o motorista respeitará o sinal. Nas transações de compra e venda, entre consumidores e empresas do comércio de bens e serviços, o crédito segue o principio de confiança. Quando se entrega um bem ou serviço mediante uma promessa de pagamento em data futura, se estabelecem uma relação de confiança entre ambas as partes envolvidas no negócio (LEONI; LEONI, 1997).

Para Sandroni (2005) crédito é a transação comercial em que um comprador recebe imediatamente um bem ou serviço adquirido, mas só fará o pagamento depois de algum tempo determinado. Essa transação pode também envolver apenas dinheiro.

Prazeres (2008 a) destaca que, é importante focar e explicar como é realizado e concedido o processo de crédito nas empresas. Pode ser definido como um facilitador existente para as vendas. Através do meio de conceder ao cliente um crédito, as empresas conseguem vender muito mais do que venderiam caso não utilizassem o mecanismo facilitador, neste contexto; o crédito. Por outro lado, pode-se considerar o crédito um fator de risco para as empresas; afinal, ela pode ter prejuízo quando concede um crédito a um cliente relapso, por exemplo.

Para Neto, Silva (1997), o objetivo conceitual de todos os modelos é obter um conjunto de informações sobre o comprador que possa demonstrar sua real capacidade de honrar os compromissos assumidos.

\subsection{Cadastro}

Da Silva (2007) explica que, na análise de crédito a base cadastral bem feita por uma empresa, pode diminuir os riscos de inadimplência, para assim poder assegurar sua rentabilidade, tornando essencial à sua sobrevivência, um cuidado especial nas decisões de concessão de crédito.

Prazeres (2008 a) baseia-se em alguns pilares para o preenchimento de um cadastro para um consumidor: identificar e localizar o cliente; verificar sua capacidade de pagamento através de sua renda e comprovar sua experiência de crédito.

Segundo o SEBRAE (2009) idealmente, podemos montar um banco de dados utilizando-se das ferramentas de informática, ou então podemos iniciar a montagem de um banco de dados de forma bem simples, montando fichas de clientes, por exemplo. Porém, a 
importância fundamental de se montar um banco de dados é gerenciar o relacionamento com seus clientes. O mais importante é valorizar o conteúdo da informação.

\subsection{Informações de créditos para os cadastros}

As centrais de informações são instrumentos importantes no apoio à gestão de risco de crédito para instituições financeiras e estabelecimentos comerciais. Elas reúnem e difundem informações de pessoas físicas e jurídicas que orientam tomadas de decisões em operações de crédito (SERASA, 2009).

Possuem também um papel disciplinador, uma vez que suas informações são amplamente divulgadas entre os estabelecimentos comerciais (SIQUEIRA, 2009).

As três etapas que o administrador financeiro deve observar na sua avaliação na concessão de crédito, segundo Da Silva (2007): é preciso obter os dados dos clientes, analisar os índices de liquidez ou decidir pela aceitação ou rejeição.

Com isso, segundo Prazeres (2008 a) a avaliação sobre a concessão de crédito concentra-se em: de quanto tempo disporá o cliente para pagar e avalia o risco do cliente face ao incremento de vendas e face aos lucros que ele pode proporcionar.

\section{METODOLOGIA}

O artigo foi elaborado através de pesquisa experimental, bibliográfica e documental, com o Demonstrativo Resultado do Exercício (DRE), em uma empresa varejista, no seguimento de Auto Mecânica do interior do Estado de São Paulo na cidade de Barra Bonita SP.

Foi promovida uma entrevista com perguntas fechadas, aos clientes e com o empresário do setor varejista. Levantou-se informações sobre a situação financeira da empresa através da ferramenta, DRE - Demonstrativo do Resultado no Exercício no ano de 2009, comparado com o ano de 2008.

Após as ações propostas, junto à construção da política de cobrança, pesquisas com os clientes consumidores, treinamentos com os colaboradores do departamento de crédito e cobrança, criando mecanismos e normas de ações efetivas para a prevenção da inadimplência, forma correta de preenchimento de cadastro, instruções na abordagem de clientes inadimplentes, criou-se fluxos de trabalhos com as ligações telefônicas, envios de cartas aos clientes inadimplentes e monitoramento de todas as ações estabelecidas, no intuito de medir a 
eficiência e os resultados (PRAZERES, 2008)

Ao término das análises, do DRE de 2008 e 2009, ficaram claros os resultados, indicando a redução da inadimplência através dos cuidados apresentados em relação à abertura do crédito e as ações promovidas no departamento de crédito e cobrança.

\section{RESULTADOS E DISCUSSÃO}

Desde sua fundação, desta empresa de Mecânica Automotiva, nunca se preocupou em providenciar uma análise de crédito dos clientes, criação de política de crédito, trabalhos preventivos de crédito e até mesmo ações corretivas de cobrança..

Leoni e Leoni (1997) dizem que quando se entrega um bem ou serviço mediante uma promessa de pagamento em data futura, se estabelecem uma relação de confiança entre ambas as partes envolvidas no negócio; neste caso a empresa confiava mas o cliente não cumpria com sua parte, na maioria das vezes, por falta de acompanhamento da área administrativa.

\subsection{Demonstrativo de resultado do exercício (DRE) sem as ações preventivas de crédito e cobrança.}

Os valores apresentados são reflexos de ações de crédito e cobrança que não eram praticados. Blatt (1999) ressalta a importância sobre cada empresa ao instituir e implantar uma política de crédito.

\begin{tabular}{|c|c|c|c|c|c|c|c|c|}
\hline & \multicolumn{2}{|c|}{ Janeiro } & \multicolumn{2}{|c|}{ Fevereiro } & \multicolumn{2}{|l|}{ Março } & \multicolumn{2}{|l|}{ Abril } \\
\hline & \begin{tabular}{|l|} 
Valor \\
\end{tabular} & $\%$ & Valor & $\%$ & Valor & $\%$ & Valor & $\%$ \\
\hline Receita Bruta & $\begin{array}{l}34.24 \\
0\end{array}$ & 100 & 37.984 & 100 & $\begin{array}{l}34.19 \\
7\end{array}$ & 100 & 32.422 & 100 \\
\hline (-) Impostos & 919 & 2,7 & 801 & 2,1 & 819 & 2,4 & 812 & 2,5 \\
\hline (=) R. Líquida & $\begin{array}{l}33.32 \\
1\end{array}$ & 97,3 & 37.183 & 97,9 & $\begin{array}{l}33.37 \\
8\end{array}$ & 97,6 & 31.603 & 97,5 \\
\hline (-) Custo & $\begin{array}{l}21.12 \\
8\end{array}$ & 91,7 & 19.190 & 50,5 & $\begin{array}{l}18.76 \\
8\end{array}$ & 54,9 & 14.221 & 43,9 \\
\hline $\begin{array}{l}\text { (=) Margem de } \\
\text { Contribuição }\end{array}$ & $\begin{array}{l}12.19 \\
3\end{array}$ & 35,6 & 17.993 & 47,4 & $\begin{array}{l}14.61 \\
0\end{array}$ & 42,7 & 17.382 & 53,6 \\
\hline (-) Despesas Fixas & 20.86 & 60,9 & 19.934 & 52,5 & 22.34 & 65,3 & 27.551 & 85,0 \\
\hline
\end{tabular}




\begin{tabular}{|c|c|c|c|c|c|c|c|c|}
\hline & 8 & & & & 1 & & & \\
\hline $\begin{array}{l}(+) \quad \text { Receitas } \\
\text { Financeiras }\end{array}$ & 0 & & 0 & & 45 & 0,10 & 22 & 0,10 \\
\hline $\begin{array}{l}(-) \quad \text { Despesas } \\
\text { Financeiras }\end{array}$ & 706 & 2,10 & 542 & 1,40 & 517 & 1,50 & 600 & 1,90 \\
\hline $\begin{array}{l}(=) \quad \text { Resultado } \\
\text { Operacional }\end{array}$ & $\begin{array}{l}- \\
9.381\end{array}$ & $-27,40$ & -2.483 & $-6,50$ & $\begin{array}{l}- \\
8.203\end{array}$ & $-24,0$ & -10.747 & $-33,1$ \\
\hline $\begin{array}{l}(-) \quad \text { Custos } \\
\text { Econômicos }\end{array}$ & 3.720 & $-10,9$ & 4.725 & $-12,4$ & 4.719 & $-13,8$ & 4.719 & $-14,6$ \\
\hline $\begin{array}{l}(=) \quad \text { Resultado } \\
\text { Econômico }\end{array}$ & $\begin{array}{l}- \\
13.10 \\
1\end{array}$ & $-38,3$ & -7.208 & $-19,0$ & $\begin{array}{l}- \\
12.92 \\
2\end{array}$ & $-37,8$ & -15.466 & $-47,7$ \\
\hline
\end{tabular}

Tabela 1: Demonstrativo do Resultado do Exercício Jan - Fev - Mar - Abr - 2008.

Fonte: Dados da pesquisa elaborada pelo autor.

Todo esse novo cenário que se desenhava, conforme Tabela 1, veio abalar a administração da empresa, começando a reestruturar toda sua área de crédito e ações em cobrança; pois nessa ciranda de comercialização os recebimentos precisam andar em dia para honrar os compromissos com fornecedores.

3.2 Demonstrativo de resultados do exercício (DRE) com as ações preventivas de crédito e cobrança

\begin{tabular}{|c|c|c|c|c|c|c|c|c|}
\hline & \multicolumn{2}{|l|}{ Janeiro } & \multicolumn{2}{|c|}{ Fevereiro } & \multicolumn{2}{|l|}{ Março } & \multicolumn{2}{|l|}{ Abril } \\
\hline & \begin{tabular}{|l|} 
Valor \\
\end{tabular} & $\%$ & Valor & $\%$ & Valor & $\%$ & Valor & $\%$ \\
\hline Receita Bruta & 49.957 & 100 & 45.706 & 100 & 55.063 & 100 & 54.945 & 100 \\
\hline (-) Impostos & -1.790 & $-3,6$ & -751 & $-1,6$ & -2797 & $-5,1$ & -2.824 & $-5,4$ \\
\hline (=) R. Líquida & 48.167 & 96,4 & 44.955 & 98,4 & 52.266 & 94,9 & 49.191 & 94,6 \\
\hline (-) Custo & $\begin{array}{l}- \\
30.245\end{array}$ & $\begin{array}{l}- \\
60,5\end{array}$ & -25.309 & $\begin{array}{l}- \\
55,4\end{array}$ & -28.407 & $-51,6$ & -32.509 & $-62,5$ \\
\hline $\begin{array}{l}(=) \quad \text { Margem de } \\
\text { Contribuição }\end{array}$ & 17.657 & 35,3 & 19.207 & 42,0 & 23.463 & 42,6 & 16.479 & 31,7 \\
\hline (-) Despesas Fixas & $\begin{array}{l}- \\
18.458\end{array}$ & $\begin{array}{l}- \\
36,9\end{array}$ & -18.842 & $\begin{array}{l}- \\
41,2\end{array}$ & -18.725 & $-34,0$ & -16.875 & $-32,4$ \\
\hline
\end{tabular}




\begin{tabular}{|l|l|l|l|l|l|l|l|l|}
\hline $\begin{array}{l}\text { (+) Receitas } \\
\text { Financeiras }\end{array}$ & 165 & 0,33 & 89 & 0,20 & 101 & 0,20 & 143 & 0,30 \\
\hline $\begin{array}{l}\text { (-) Despesas } \\
\text { Financeiras }\end{array}$ & -405 & $\begin{array}{l}- \\
0,81\end{array}$ & -389 & - & -524 & -095 & -602 & $-1,10$ \\
\hline $\begin{array}{l}\text { (=) Resultado } \\
\text { Operacional }\end{array}$ & -1041 & - & 65 & 0,14 & 4.315 & 7,83 & -855 & $-1,56$ \\
\hline $\begin{array}{l}\text { (-) Custos } \\
\text { Econômicos }\end{array}$ & -1.809 & - & -1.978 & - & -802 & $-1,46$ & -1.105 & $-2,01$ \\
\hline $\begin{array}{l}\text { (=) Resultado } \\
\text { Econômico }\end{array}$ & $-\mathbf{2 8 5 0}$ & - & $-\mathbf{- 1 . 9 1 3}$ & - & $\mathbf{3 . 5 1 3}$ & $\mathbf{6 , 3 8}$ & $\mathbf{- 1 . 9 6 0}$ & $\mathbf{- 3 , 5 7}$ \\
\hline
\end{tabular}

Tabela 2: Demonstrativo do Resultado do Exercício Jan - Fev - Mar - Abr - 2009.

Fonte: Dados da pesquisa elaborada pelo autor.

A primeira ação trabalhada foi à elaboração de um cadastro e nas vendas à prazo trabalhou-se a estrutura preventiva mais importante, a realidade da renda do cliente para com o valor empregado em seu consumo; concomitantemente foi elaborado um limite de crédito para cada cliente que consumia à prazo sem nenhuma garantia de pagamento. Segundo Prazeres (2008 b) alguns itens importantes para a composição do cadastro foram utilizados na elaboração do cadastro para os clientes, tais como: não abreviar o nome do cliente, preencher o cadastro completamente, anotar todos os telefones e endereços possíveis para localização do cliente, local de trabalho, estado civil e número dos documentos. Nas compras à vista foi solicitada apenas um número de telefone para contato e endereço residencial, utilizando essa informação para um trabalho de marketing, futuramente.

Apesar de toda essa análise, antes da implantação, houve alguns clientes que se queixavam ao preencher o cadastro, comentavam que nunca tiveram que esperar para preenchimento desse tipo de cadastro dentro da empresa.

Da Silva (2007) aponta que esses tipos de créditos apresentados podem ser utilizados pelos empresários nas pequenas empresas varejistas, oferecendo aos seus clientes consumidores mais segurança, evitando assim transtornos com fichas cadastrais vendidas à prazos.

Com o intuito de não deixar a inadimplência crescer, criou-se regras de cobrança efetiva. Diante das informações de Prazeres (2008 b) onde mostra como se deve implantar uma rotina no setor de cobrança, a empresa partiu para a construção dessa rotina: entre 5 e 10 dias de atraso, a empresa fará contato por telefone; o segundo contato e aviso serão efetuados através de uma carta com teor um pouco mais intenso; entre 26 e 30 dias de atraso, telefonar 
ou enviar carta informando que será registrado no SPC, caso não efetue o pagamento; não havendo contato do cliente para com a empresa após todos esses envios de informativos e cobrança, um funcionário da empresa fará o contato pessoalmente.

\section{CONCLUSÕES}

Através da pesquisa desse artigo e dentro da fundamentação dos autores, foi possível visualizar que existem formas de amenizar e prevenir o risco de inadimplência nas pequenas empresas varejistas, utilizando as ferramentas e modernizando os métodos de avaliação de crédito sem interferência nas vendas, evitando assim uma possível falência das pequenas empresas.

Vale ressaltar ainda, a grande e fundamental importância das pequenas e médias empresas se cadastrarem nas instituições de pesquisas de varejo, pois, são esses tipos de instituições que poderão apresentar números de queda ou alta de inadimplência.

Outro resultado interessante foi à melhoria da qualidade das informações prestadas aos clientes, através das faturas implantadas, relação de serviços com preços e prazos de pagamentos, emissão de boletos e a busca de parcerias com cartões de créditos e financeiras.

Com esse estudo pode-se compreender as dificuldades das pequenas empresas varejistas, quanto ao fato de implantarem novidades ou mudanças para adequação de sua realidade ao mercado competitivo, porém, há de entender-se que se faz necessário um bom planejamento, uma boa estrutura, uma boa conversa com os colaboradores, antes de qualquer atitude a ser tomada, principalmente quando se trata do fato de mexer com o principal elemento da economia, o cliente.

\section{REFERÊNCIAS BIBLIOGRÁFICAS}

BLATT, Adriano. Cobrança por Telefone e Negociação com Inadimplentes. 1. ed. São Paulo: Nobel 1999.

BRAGA, Renato. Fundamentos e Técnicas da Administração Financeira. 1. ed. São Paulo: Atlas,1989. 
DA SILVA, Rubens Filinto. Chega de Inadimplência - Cobrança e Recuperação de Valores. 1. ed. São Paulo: Pilares, 2007.

LEONI, Geraldo; LEONI, Evandro Geraldo. Cadastro, Crédito e Cobrança. São Paulo: Atlas, 1997.

NETO, Alexandre Assaf; SILVA, César Tibúrcio. Administração do Capital de Giro. 2 ed. São Paulo: Atlas, 1997.

PRAZERES, Hélvio T. Cury. Análise de Crédito e Cobrança na Pequena Empresa. Parte 1 Viçosa-MG: CPT-Centro de Produções Técnicas, 2008 a, 418p.

PRAZERES, Hélvio T. Cury. Análise de Crédito e Cobrança na Pequena Empresa. Parte 2 Viçosa-MG: CPT-Centro de Produções Técnicas, 2008 b, 200p.

SANDRONI, Paulo. Dicionário de Economia do Século XXI. Edição do Novíssimo Dicionário de Economia. Rio de Janeiro: Editora Record, 2005.

SEBRAE. Cadastros de Clientes. Disponível em: http://www.sebraesp.com.br/faq/marketing/equipe_tecnicas_vendas/montar_cadastro_clientes . Acesso em 01 set. 2009.

SEBRAE. Concessão de Crédito a Clientes. Disponível em: http://www.biblioteca.sebrae.com.br/bds/BDS.nsf/35E5ED16CE3F0A9503256F9E00498E72 /\$File/NT000A3882.pdf . Acesso em 28 ago. 2009.

SEBRAE. Inadimplência: Como Evitar e Resolver. Disponível em: http://www.sebraesp.com.br/search/node/inadimpl\%AAncia. Acesso em 17 fev. 2009.

SEBRAE/RJ. Cuidado com a Inadimplência. Disponível em: http://comunidades.rj.sebrae.com.br/boletim/?p=672. Acesso em 02 set. 2009.

SERASA, Inadimplência das Empresas Inicia 2009 em Alta. Disponível em: http://www.serasa.com.br/empresa/noticias/2009/noticia_0660.htm. Acesso em 06 fev. 2009. 
SIQUEIRA, Denis. Novas Atribuições para Crédito e Cobrança. Disponível em: http://www.creditoecobranca.com/Artigo10.asp. Acesso em: 07 fev. 2009. 